Relato de Experiência ${ }^{1}$

\title{
TRANSFORMAÇÕES GEOMÉTRICAS EM PONTO CRUZ EM OFICINA NO LABORATÓRIO DE MATEMÁTICA COM ALUNAS DO PROGRAMA MULHERES MIL
}

\author{
Sabrine Costa Oliveira \\ Licenciada em Matemática no IFES/Vitória \\ binecosta@gmail.com \\ Sandra Aparecida Fraga da Silva \\ Professora, IFES/Vitória/EDUCIMAT \\ sandrafraga7@gmail.com
}

\begin{abstract}
Resumo
O relato aborda o desenvolvimento de uma oficina que teve por objetivo explorar transformações geométricas no plano em bordados de ponto cruz junto aos participantes do Projeto Mulheres Mil no Instituto Federal do Espírito Santo. Essa temática faz parte de uma pesquisa de iniciação científica que investigou as isometrias no plano por meio dos bordados em ponto cruz. Nos bordados em ponto cruz observamos e trabalhamos propriedades que representam potencialidades pedagógicas face aos conceitos geométricos. Desenvolveu-se junto aos participantes do Projeto Mulheres Mil uma abordagem diferenciada no trato com a geometria enfatizando as transformações geométricas, criando novas possibilidades e alternativas para o ensino da Matemática.
\end{abstract}

Palavras-chave: Transformações geométricas, Arte, Ponto cruz, Mulheres Mil, Ensino de matemática.

\section{GEOMETRIC TRANSFORMATIONS IN POINT CROSS IN THE LABORATORY WORKSHOP MATH PROGRAM STUDENTS WITH A THOUSAND WOMEN}

\begin{abstract}
The report discusses the development of a workshop aimed at exploring geometric transformations in the plane of cross stitch embroidery with the participants of the Thousand Women Project at the Federal Institute of the Holy Spirit. This theme is part of a study lead by investigating the isometrics in the plane by means of cross-stitch embroidery. In cross-stitch embroidery work and observe properties that represent the pedagogical relation to geometric concepts. Developed among the participants of the Thousand Women Project a differentiated approach in dealing with the geometry emphasizing geometric transformations, creating new possibilities and alternatives for the teaching of mathematics.
\end{abstract}

Keywords: Geometric Transformations, Art; Cross stitch, Thousand Women, Teaching math.

\footnotetext{
${ }^{1}$ Boletim Gepem (Online) ISSN: 2176-2988 | n. 64 - Jan./Jun. 2014 (texto em diagramação).
} 


\section{Introdução}

O presente trabalho relata uma experiência didática vivenciada durante o mês de fevereiro de 2013 em duas turmas do Programa Mulheres Mil no Instituto Federal do Espírito Santo - Campus Vitória. A oficina foi aplicada no contexto de uma pesquisa de iniciação científica do Programa Institucional Voluntário de Iniciação Científica - PIVIC, que estuda as transformações geométricas por meio dos bordados em ponto cruz.

O Programa Mulheres Mil faz parte das ações do Programa Federal Brasil Sem Miséria e tem como objetivo principal promover o acesso à educação profissional de mulheres em vulnerabilidade social, com baixa escolarização, de acordo com as necessidades educacionais de cada comunidade e com a vocação socioeconômica de cada região. No IFES - Campus Vitória, o programa atende cerca de 100 mulheres nos turnos vespertino e noturno e a proposta do curso inclui aulas de Informática, Português, Matemática, Espanhol, Inglês, Direitos e Saúde da Mulher, Ética e Cidadania, e Economia Solidária para as paneleiras de Goiabeiras.

As alunas dessas turmas, em sua maioria, faziam parte das Paneleiras de Goiabeiras, assim chamadas por ser a maioria dos artesãos mulheres e residirem no bairro de Goiabeiras, em Vitória/ES, fabricam em barro: panelas, potes, travessas, bules, caldeirões, frigideiras de diversas formas e tamanhos. O ensinamento é transmitido de pais para filhos e permite que a identidade cultural dessa atividade seja mantida com quase nenhuma alteração há várias gerações.

Nesse contexto, este artigo apresenta uma experiência de ensino de matemática desenvolvida por meio da aplicação de atividades didáticas criadas para o estudo das transformações geométricas subjacentes aos bordados em ponto cruz no Programa Mulheres Mil. Ressaltamos que a proposta inicial da iniciação científica não foi realizar esse trabalho, mas desenvolver atividades com esta temática para a formação inicial de professores e para alunos da escola pública que participam do Programa Institucional de Bolsas de Iniciação à Docência - Pibid ${ }^{2}$.

\footnotetext{
${ }^{2}$ Maiores informações sobre este trabalho de Iniciação Científica ver em: http://pse.ifes.edu.br/prppg/pesquisa/jornadas/Jornada_2011_2012/anais/anais.htm
} 


\section{Referencial Teórico}

Observamos em documentos oficiais como o PCN de matemática (BRASIL, 1997) e o Guia do livro didático de matemática - PNLD (BRASIL, 2010) - a aposta em um ensino baseado na interdisciplinaridade, como princípio pedagógico que estabelece conexões entre áreas de conhecimentos. Os mesmos recomendam que o ensino de geometria seja articulado com a arte.

A utilização do bordado em ponto cruz foi uma maneira encontrada para concretização da matemática. Esse estudo é importante tanto na criação da sensibilidade quanto para o desenvolvimento do raciocínio geométrico. Segundo os Parâmetros Curriculares Nacionais:

O aluno que conhece arte pode estabelecer relações mais amplas quando estuda um determinado período histórico. Um aluno que exercita continuamente sua imaginação estará habilitado a construir um texto, a desenvolver estratégias pessoais para resolver um problema matemático (BRASIL, 1997, p.14).

A análise de transformações geométricas no plano, tais como simetrias, translações e rotações são fontes ricas para o desenvolvimento de atividades geométricas em sala de aula. Investigando a matemática que está presente nos diversos campos da atividade humana, no nosso caso em bordados em ponto cruz, notamos que contribui tanto na estrutura do pensamento quanto no progresso do raciocínio dedutivo. Já a arte proporciona a expansão do universo cultural dos indivíduos, abrindo espaço à participação social, mobilizando sentidos e capacidades como imaginação e observação.

Os processos de ensino e aprendizagem da matemática, por muitos anos e ainda hoje, estão ligados à repetição de exercícios e memorização de fórmulas, tarefas que para os alunos está associado a sofrimentos e fracassos escolares. Ao trazermos a arte para a sala de aula de matemática é possível transformar o ambiente escolar em um espaço de criação, prazer, construção de conhecimentos e de descobertas. E ainda, espera-se que os alunos:

\footnotetext{
Além de desenvolver a intuição e a imaginação, matemática e arte são disciplinas fundamentais por muitas outras razões. Por exemplo, a matemática é uma área naturalmente propícia ao desenvolvimento e à manutenção de um diálogo permanente com a vida e com outras áreas do conhecimento (FAIGUELERNT; NUNES, 2006, p.15).
}

A Matemática e a Arte se integram em diversos caminhos auxiliando o desenvolvimento do pensamento crítico, da autonomia intelectual, da sensibilidade e da criatividade. E ao unir o estudo da Geometria à Arte aperfeiçoam-se habilidades de percepção e de visualização de conceitos geométricos. Segundo os Parâmetros Curriculares 
Nacionais precisamos relacionar o estudo da geometria com o mundo físico, com "obras de arte pinturas, desenhos, esculturas e artesanato, de modo que permita ao aluno estabelecer conexões entre a Matemática e outras áreas do conhecimento” (BRASIL, 1998, p.51).

Nessa mesma vertente, Eduardo Veloso (2012) aponta a importância de estudarmos a matemática existente em diferentes artes decorativas, no nosso caso, escolhemos o artesanato manual de ponto cruz, algo conhecido por pertencer a cultura do Brasil. Destacamos artesanato manual, visto que, atualmente, existem artesanatos que são produzidos em máquinas industrializadas, como o próprio bordado. Esse autor afirma que

[...] pode dizer-se que a matemática, quando interpreta uma certa realidade, por exemplo as figuras da arte decorativa produzida desde há milhares de anos por povos de todo o mundo, procura encontrar regularidades que conduzam a processos de classificação e organização dos objetos dessa realidade (VELOSO, 2012, p. 50).

Diante do citado acima, consideramos que o estudo das transformações geométricas torna-se mais prazeroso aliado as artes, pois permite que o aluno visualize propriedades e conceitos geométricos facilitando a compreensão desse conteúdo de geometria.

\section{Metodologia}

Em dois anos de pesquisa de iniciação científica, realizamos pesquisas bibliográficas sobre as transformações geométricas e sua ligação com a arte. Em seguida, analisamos os bordados em ponto cruz e estudamos as transformações existentes.

Com essa investigação elaboramos fichas de atividades, ordenadas pelo grau de dificuldade que normalmente surge quando o assunto é estudado. Essas atividades foram criadas com o auxílio do programa PC-Stitch, que é um software gratuito que permite criar gráficos em ponto cruz e nos auxiliou na criação e adaptação de gráfico e na produção de atividades que foram aplicadas nas oficinas.

Nossa participação no Programa Mulheres Mil ocorreu por meio de um convite da coordenadora e da professora de matemática do projeto, que devido à necessidade de contemplar matemática de forma dinâmica, nos convidou para ministrar uma oficina para cada turma do projeto. Cada oficina teve duração de 3 horas e teve por objetivo no programa evidenciar a matemática presente no cotidiano de muitas alunas, pois acreditamos que mesmo quem não sabe bordar, ao menos conhece o bordado em ponto cruz. A seguir apresentamos algumas figuras das atividades contidas nas fichas. 


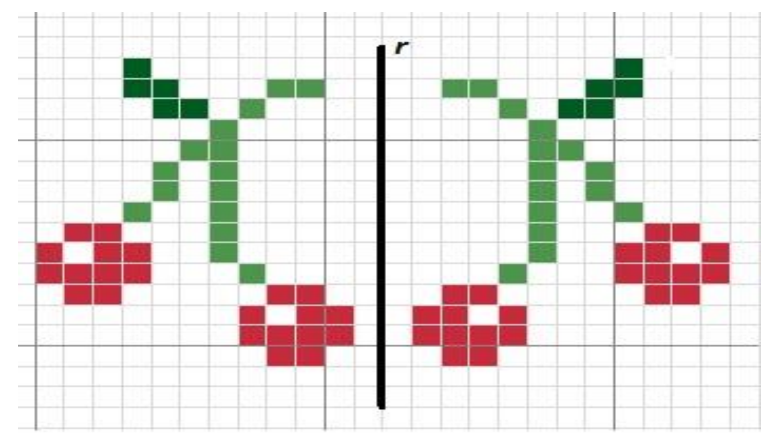

Figura 1. Gráfico para identificar qual transformação foi aplicada.

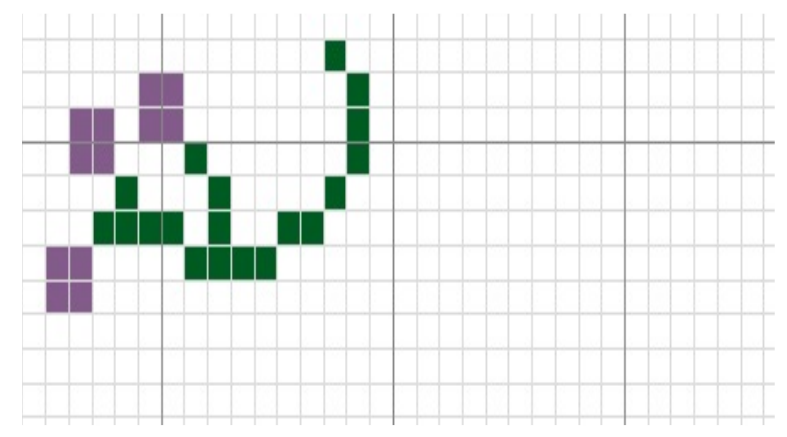

Figura 2. Gráfico com atividade de reflexão.

As atividades solicitava que o participante completasse o gráfico com a transformação geométrica pintando com lápis de cor e depois aplicamos as transformações geométricas nos bordados manualmente. As barras de étamine já estavam iniciadas, devido o pouco tempo e visando agilizar o trabalho.

\section{Desenvolvimento}

Conforme já dito anteriormente, aplicamos as fichas de trabalho separadas por tipo de transformação geométrica com duas turmas do Programa Mulheres Mil, nos turnos vespertino e noturno. Ao iniciar a aula do dia 28 de fevereiro de 2013, a professora de matemática do programa Mulheres Mil, comunicou aos alunos de que nós aplicaríamos em forma de oficina, nossa pesquisa de iniciação científica.

Iniciamos a oficina, com algumas perguntas do tipo: Alguém já ouviu alguma das palavras reflexão, translação ou rotação? Alguns participantes sem conceituar responderam que tinha haver com os movimentos da terra. A partir dessa discussão, definimos intuitivamente os conceitos de eixo de simetria e reflexão. E a partir de um desenho em uma folha de papel explicamos que ao dividirmos uma figura plana em duas partes iguais e se essas partes ao serem dobradas coincidissem, então o vinco feito na folha é chamado eixo de simetria. Realizamos atividades para traçar o eixo de simetria de figuras planas diversas e em gráficos de ponto cruz (fig. 3 e 4). 

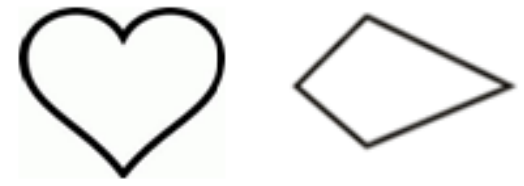

Figura 3. Atividade para traçar o eixo de simetria em figuras planas.
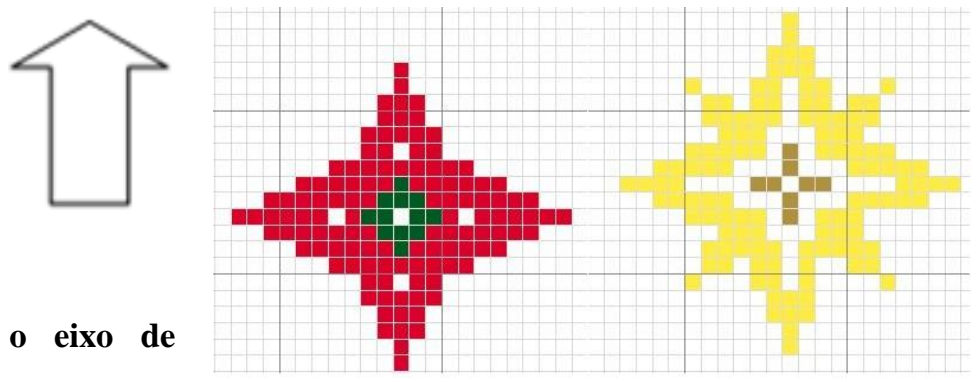

Figura 4. Atividade para traçar o eixo de simetria em gráficos de ponto cruz.

Em seguida, conceituamos intuitivamente reflexão fazendo uma discussão sobre o porquê que nos carros do corpo de bombeiro ou ambulância os nomes estão escritos invertidos. A partir dessa associação, conceituamos reflexão como a transformação geométrica plana que ocorre através de uma reta chamada eixo. O ponto original e seu correspondente na reflexão possuem a mesma distância em relação ao eixo. Continuando, aplicamos esses conceitos em atividades nos gráficos em ponto cruz (fig. 5 e 6 ).

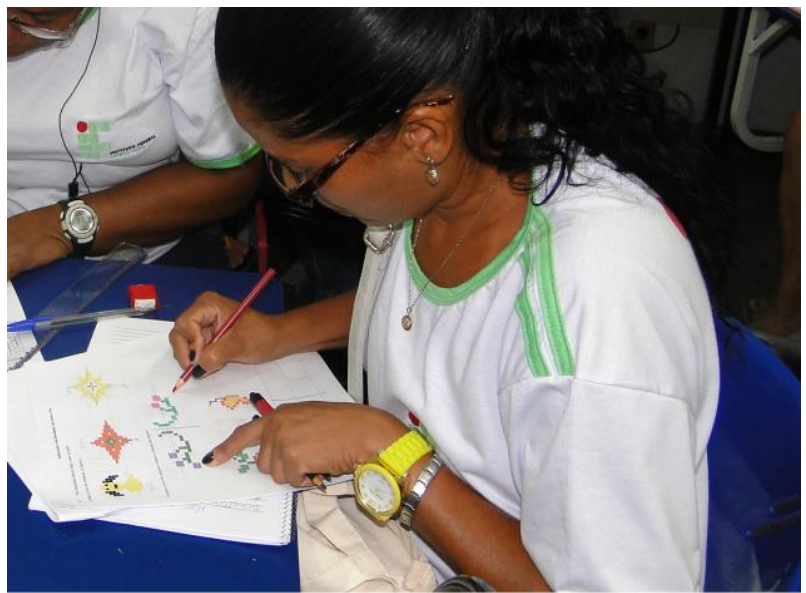

Figura 5. Aluna do programa realizando atividades de reflexão no gráfico em ponto cruz.

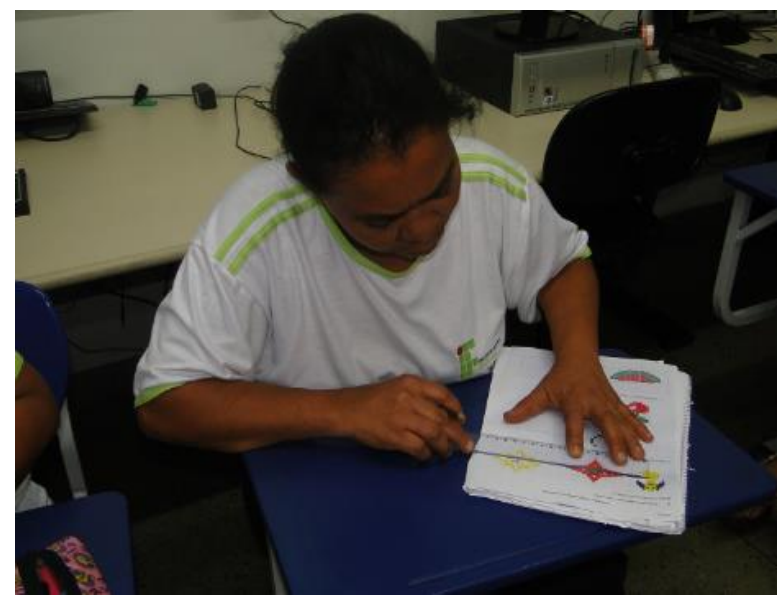

Figura 6. Aluna do programa realizando atividade de eixo de simetria no gráfico em ponto cruz.

Após conceituarmos eixo de simetria e reflexão, demos continuidade à oficina conceituando translação e rotação. Definimos translação como uma transformação geométrica que desloca a figura original, segundo uma direção, um sentido e um comprimento. A translação transforma uma figura original em outra figura. Já a rotação foi definida como o movimento que modifica uma figura original a partir de um giro, tendo sido determinados o centro, um ângulo e o sentido do giro (fig. 7 e 8). 


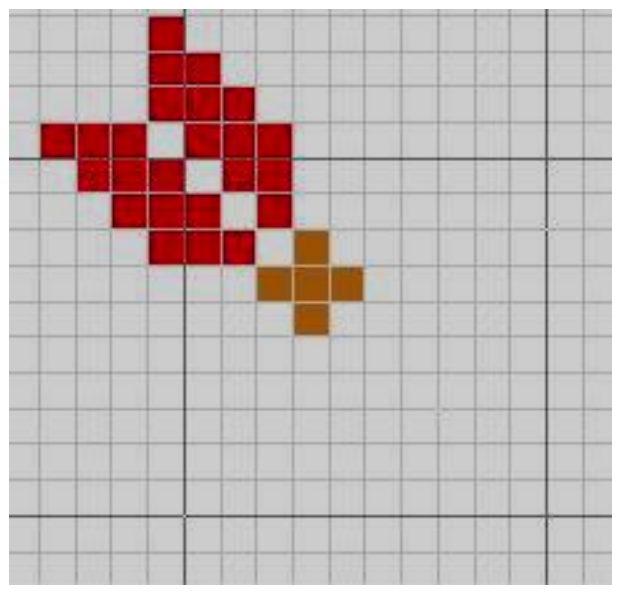

Figura 7. Atividade de rotação da pétala da flor.

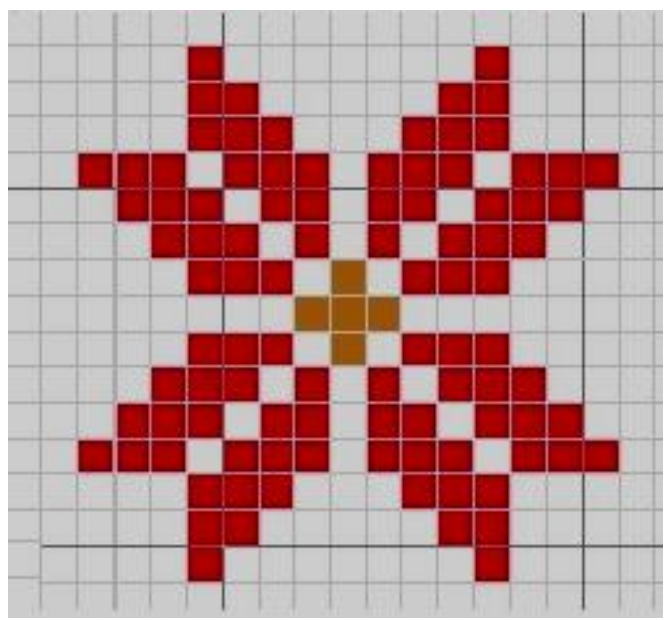

Figura 8. Flor completa aplicando três rotações sucessivas de $90^{\circ}$ no sentido horário.

Depois de trabalharmos todos os conceitos e aplicarmos as transformações nos gráficos em ponto cruz, iniciamos os bordados manuais na étamine. Como já dito anteriormente, as barras de étamine já estavam iniciadas para agilizar a execução. Muitas das participantes conheciam a prática do bordado em ponto cruz e conseguiram desenvolver os bordados propostos aplicando as transformações geométricas estudadas (fig. 9 e 10).

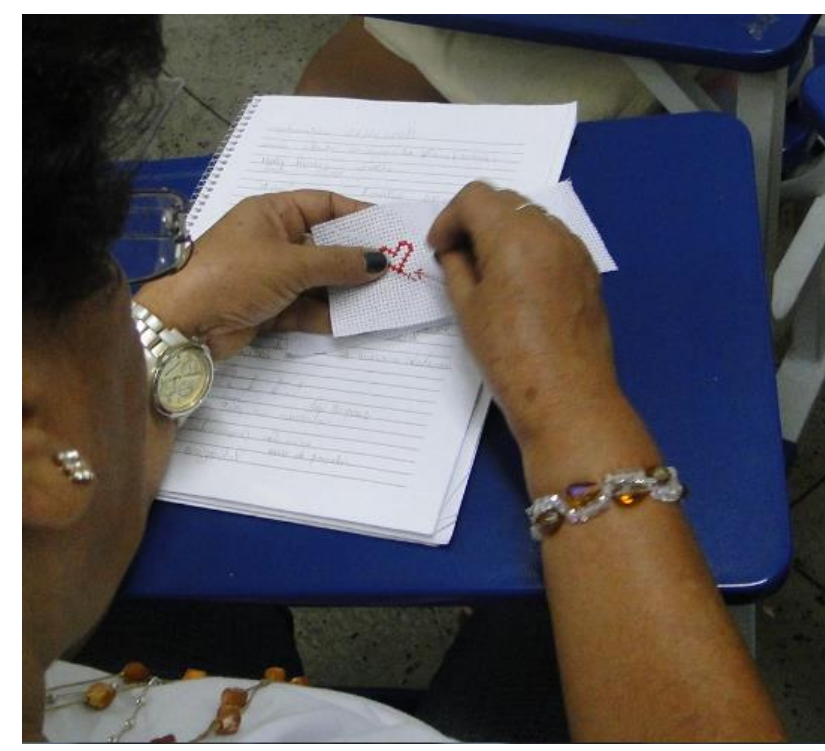

Figura 9. Participante iniciando o bordado com a rotação de $90^{\circ}$ no sentido horário do coração.

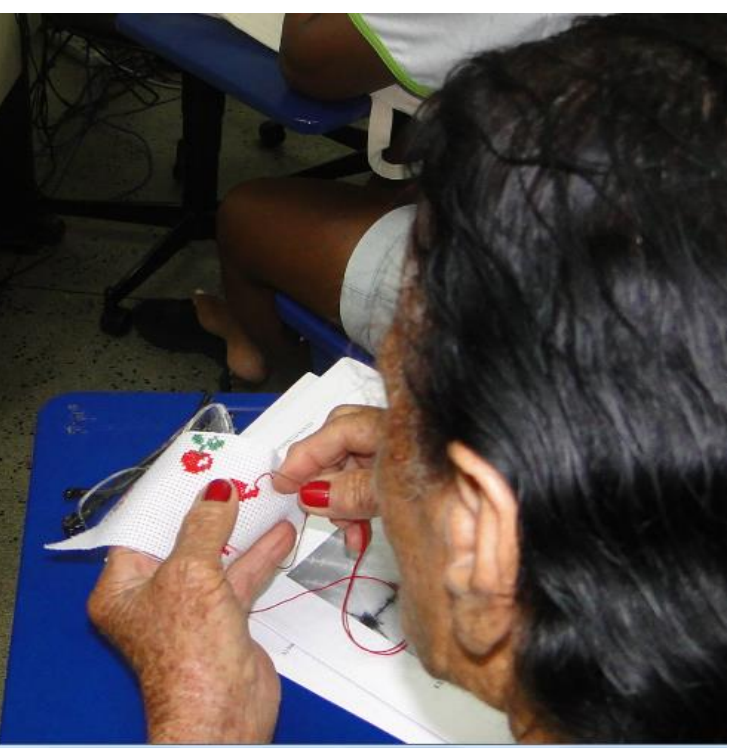

Figura 10. Participante bordando uma maça transladada no sentido horizontal.

É importante dizer que todos os conceitos trabalhados nessa oficina foram construídos a partir de exemplos de forma intuitiva para alcançar o objetivo inicial de trabalhar a matemática presente no cotidiano das participantes. Cabe salientar que ao fim da oficina, as participantes estavam fascinadas com nossa proposta de explorar a 
matemática nos bordados em ponto cruz e afirmavam que não tinham percebido anteriormente a matemática presente nesse artesanato.

\section{Considerações Finais}

Neste trabalho notamos a importância de buscar novas atividades para o ensino da matemática, em especial para o ensino da geometria, que se mostra com necessidades especiais. Pois, segundo Catunda (1988) os professores não dominam os conceitos da geometria, influenciados pela geometria que eles tiveram e, por isso, a excluem de seus planos de aula. Pensando nisso, precisamos buscar ferramentas diversas para auxiliar os alunos a construírem, com mais facilidade, os conceitos geométricos relacionados a transformações geométricas no plano. Nas oficinas realizadas os participantes ficaram fascinados por perceberem e identificarem algumas possibilidades que o ponto cruz apresenta para o estudo de geometria. Algo novo para essas mulheres que não estavam habituadas a trabalhar a matemática em algo conhecido e vivenciado por elas.

Pretendemos, por meio dos bordados em ponto cruz, propor novas possibilidades para o ensino da Matemática que favoreçam a criatividade e o prazer por aprender, numa perspectiva de ensino contextualizado a algo que faz parte da cultura do Brasil.

\section{Referências}

http://www.ifes.edu.br/noticias/3516-campus-vitoria-inicia-curso-destinado-as-paneleirasde-goiabeiras Acesso em outubro de 2013.

http://mulheresmil.mec.gov.br/index.php?option=com_content\&view=article\&id=47\&Ite mid=53\&lang=br Acesso em outubro de 2013.

BRASIL, Secretaria de Educação Fundamental. Parâmetros Curriculares Nacionais: Artes. Brasília: MEC/SEF, 1997.

Secretaria de Educação Fundamental. Parâmetros Curriculares Nacionais: Matemática. Brasília: MEC/SEF, 1998.

Secretaria de Educação Fundamental. Guia do Livro Didático: PNLD 2010: Alfabetização Matemática e Matemática. Brasília: MEC/SEF, 2009.

CATUNDA, Omar et al. As transformações geométricas e o ensino de geometria. Salvador: Centro Editorial e Didático da UFBA, 1988.

FAINGUELERNT, Estela Kaufman; NUNES, Kátia Regia Ashton. Fazendo Arte com a Matemática. Porto Alegre: Artmed, 2006. 
VELOSO, Eduardo. Simetria e transformações geométricas. Lisboa: Associação de Professores de Matemática - APM, 2012.

Recebido em fevereiro de 2014 Aprovado em abril de 2014 